\title{
Solubility and Diffusivity of Methylmethacrylate and Butylacrylate Monomers in a MMA-BA Copolymer
}

\author{
YILMAZ YUREKLI, ${ }^{1}$ SACIDE ALSOY ALTINKAYA, ${ }^{1}$ JOHN M. ZIELINSKI ${ }^{2}$ \\ ${ }^{1}$ Department of Chemical Engineering, Izmir Institute of Technology, Gulbahce Koyu, Urla-Izmir 35437, Turkey \\ ${ }^{2}$ Air Products and Chemicals, 7201 Hamilton Boulevard, Allentown, Pennsylvania 18195
}

Received 18 December 2006; accepted 19 February 2007

DOI: 10.1002 / polb.21189

Published online in Wiley InterScience (www.interscience.wiley.com).

\begin{abstract}
Mutual diffusion coefficients and sorption isotherms of methyl methacrylate (MMA) and butyl acrylate (BA) monomers in methyl methacrylate-butyl acrylate copolymer (MMA-BA) have been measured by gravimetric sorption. MMA is found to have higher solubility and diffusion rates in the copolymer than BA. Sorption data for MMA were interpreted using classical Flory-Huggins thermodynamic theory with a constant interaction parameter $(\chi)$. A modified version of this theory has been applied to correlate the sorption data of $\mathrm{BA}$, which exhibit a temperature and concentration-dependent $\chi$ parameter. For MMA, the isotherm data reveal enhanced polymer-solvent interactions with increasing temperature, while for BA the data indicate a drive toward phase separation with increasing temperature. Despite the difference in thermodynamic behavior, both monomers are found to exhibit Fickian diffusion and the diffusivity data are correlated reasonably well with the Vrentas-Duda free volume theory. Some deviation between the free-volume correlation and the experimental data is observed at the lowest temperature and BA concentration examined. @ 2007 Wiley Periodicals, Inc. J Polym Sci Part B: Polym Phys 45: 1996-2006, 2007

Keywords: BA; butyl acrylate; diffusion; Flory Huggins theory; gravimetric sorption; isotherm; methyl methacrylate; methyl methacrylate-butyl acrylate copolymer; MMA; modeling; monomers; mutual diffusivity; sorption; thermodynamics; Vrentas-Duda free volume theory
\end{abstract}

\section{INTRODUCTION}

Incomplete polymerization, impurities within monomers and undesirable secondary reactions during polymer synthesis all lead to residual volatile organic compounds (VOCs) in the finished product. Because of tight environmental regulations and health standards, strong pressure is imposed on manufacturers to lower the levels of volatile impurities in polymers. The volatile residues are usually removed by vacuum or steam stripping of

Correspondence to: S. A. Altinkaya (E-mail: sacidealsoy@ iyte.edu.)

Journal of Polymer Science: Part B: Polymer Physics, Vol. 45, 1996-2006 (2007) @O2007 Wiley Periodicals, Inc.

1996 a polymer melt or of polymer particles in a devolatilization unit. The design and optimization of the polymerization reactors and devolatilization units require thermodynamic and diffusivity data. A comprehensive survey of the literature indicates that measurements of diffusion of monomers in polymers are usually limited to high monomer concentration self-diffusion data which may only be useful to predict the diffusion rates in the dilute polymer concentration regime, far from the region of interest in devolatilization. ${ }^{1-3}$ In addition, Gilbert ${ }^{4}$ has reported that the free radical polymerization kinetics can be diffusion-controlled especially at intermediate to high conversion.

The analysis of both devolatilization and polymerization processes requires mutual diffusion 
data over a wide range of temperature and concentration. The measurement of monomer sorption at elevated temperatures involves a high risk due to a possibility of polymerization during the experiment. Thus, a reliable method for extrapolating the low temperature data to high temperatures is of considerable practical importance. For many years, Vrentas-Duda free-volume theory has provided a useful framework for both correlating and predicting self-diffusion and binary mutual-diffusion coefficients as a function of both temperature and concentration. ${ }^{5,6}$ In this work, we first measure the solubility and diffusivity of two monomers, methyl methacrylate (MMA) and butyl acrylate (BA), in their copolymer methyl methacrylate-butyl acrylate (MMA-BA) and then analyze the diffusion data with Vrentas and Duda free volume theory. In addition, we correlate the equilibrium isotherms with the original FloryHuggins equation as well as a modified form of this model which considers a concentration and temperature-dependent $\chi$ parameter. The data reported here are of interest especially for the paint industry since the copolymer used in this study is added as a binder during the production of acrylic based paints.

\section{EXPERIMENTAL}

\section{Materials and Sample Preparation}

MMA (CAS-register number 80-62-6) and BA (CAS-register number 141-32-2) monomers were supplied by Organik Kimya A.S., Turkey. The MMA-BA copolymer used in this study is produced by the same company in the form of an emulsion consisting of $50 \%$ water and $50 \%$ copolymer by volume. Films of the copolymer were prepared by casting the emulsion on a clean and smooth glass substrate through an automatic film applicator (Sheen Instruments Ltd., model number 1133 N) and then removing most of the water over the course of $30 \mathrm{~min}$ in a vacuum oven maintained at $40{ }^{\circ} \mathrm{C}$. The film was removed from the glass substrate by immersing the sample in a water bath maintained at a temperature of $40{ }^{\circ} \mathrm{C}$. The films were then heated in a stepwise manner, first to $125{ }^{\circ} \mathrm{C}$ for one day and then to $140{ }^{\circ} \mathrm{C}$ for 3 days under vacuum to remove all residuals and relax stresses induced by film formation. The dry film thickness was measured at different locations using a micrometer and the average of these measurements was used for subsequent calculations.

Journal of Polymer Science: Part B: Polymer Physics DOI 10.1002/polb
The results obtained from the micrometer were confirmed with scanning electron microscope (Philips XL-30SFG) measurements.

The glass transition temperature of the copolymer was measured by differential scanning calorimetry (DSC) with a Shimadzu Model No 50. Samples were heated from 20 to $600{ }^{\circ} \mathrm{C}$ at a heating rate of $10{ }^{\circ} \mathrm{C} / \mathrm{min}$ under $\mathrm{N}_{2}$. The composition of the copolymer was determined by comparing the intensities of the $-\mathrm{OCH}_{3}$ and $-\mathrm{OCH}_{2}$ proton resonances on the ${ }^{1} H$ nuclear magnetic resonance (NMR) spectra at $302 \mathrm{~K}$ in a deuteriochloroform $\left(\mathrm{CDCl}_{3}\right)$ solution using a Varian type spectrometer operating at $400 \mathrm{MHz}$. The parameters for the proton spectra were as follows: spectral width: 6000 $\mathrm{Hz}$, acquisition time: $3.729 \mathrm{~s}$.

\section{Experimental Setup and Procedure}

We have employed a sorption apparatus using a magnetic suspension balance (MSB) first developed by Kleinrahm and Wagner. ${ }^{7}$ Operating principles and advantages of the magnetic suspension balance compared to conventional gravimetric sorption devices have been previously discussed. ${ }^{8}$ Figure 1 shows a schematic of the experimental set-up which consists of three main parts: a sorption column, a control unit and a solvent delivery system. During a typical sorption experiment, small pieces of thin films were placed inside a sample holder consisting of five trays and the holder was suspended from a permanent magnet in a thermally insulated sorption chamber. The column was maintained at a constant temperature using a double tube thermostat (accuracy: $\pm 0.5{ }^{\circ} \mathrm{C}$ ) Prior to sorption, the sample was degassed for a period of at least $24 \mathrm{~h}$ at the analysis temperature. Solvent vapor was prepared in a solvent flask placed into a constant temperature bath (accuracy: \pm $0.5{ }^{\circ} \mathrm{C}$ ). The vapor pressure of the solvent was

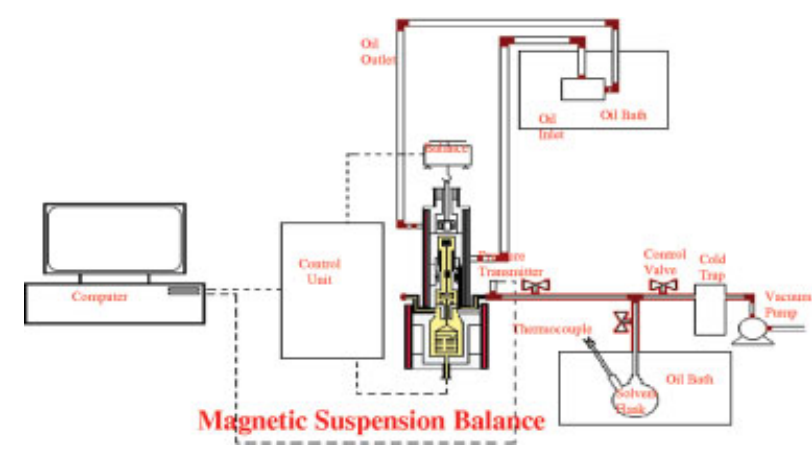

Figure 1. Flowsheet of the gravimetric sorption apparatus. 
measured by a pressure transducer (Omega DPG1000B-15A accuracy: $0.25 \%$ full scale) operating within a range of vacuum up to $1 \mathrm{~atm}$. To prevent condensation of solvent vapor, heating tape was used on all solvent vapor lines. During each sequential runs, the vapor pressure of the solvent was increased incrementally so that the difference between the initial and equilibrium weight of the solvent in the polymer was small. This minimizes film swelling during the course of an experiment and enables one to better estimate a constant diffusion coefficient at an average solvent concentration. The balance used in our study has a pressure range of 0-150 bars and temperature range up to $250{ }^{\circ} \mathrm{C}$ with an accuracy of $\pm 2 \mu \mathrm{g}$. The small step sizes applied and the limited solubility of the solvents in the polymers lead to small weight uptakes, in which case, the buoyancy effect cannot be neglected. We have corrected the raw data for buoyancy using following equation:

$$
\begin{array}{r}
m_{\text {absorbed }}=S_{\mathrm{MP}}+\rho_{\text {vapour }}\left\lfloor V_{\text {cage }+ \text { hook }}+V_{\text {sample }+ \text { vapour }}\right. \\
\left.+V_{\text {sampleholder }}\right\rfloor-m_{\text {vacuum }}
\end{array}
$$

Where $S_{\mathrm{MP}}$ denotes the weight measured by the balance, $\rho_{\text {vapor }}$ is the density of the solvent vapor calculated at the penetrant vapor pressure and temperature using the ideal gas law, $V_{\text {cage+hook }}$, $V_{\text {sample+vapor, }}$ and $V_{\text {sampleholder }}$ are the volumes of the suspension unit, the sample including the vapor absorbed, and the sample holder, respectively, and $m_{\text {vacuum }}$ is the weight measured under vacuum.

\section{THEORY}

\section{Determination of Diffusion Coefficients}

The analysis of differential step-change sorption experiments is usually based on an analytical expression for fractional mass uptake curve given by eq 2 below. ${ }^{9}$

$$
\begin{aligned}
\frac{M_{t}-M_{\mathrm{o}}}{M_{\infty}-M_{\mathrm{o}}}=1- & \frac{8}{\pi^{2}} \sum_{\mathrm{m}=0}^{\infty} \frac{1}{(2 m+1)^{2}} \\
& \times \exp \left(-D(2 m+1)^{2} \pi^{2} t / 4 L^{2}\right)
\end{aligned}
$$

where $M_{\mathrm{o}}, M_{\mathrm{t}}$ and $M_{\infty}$ are the initial amount of penetrant in the film, mass of the penetrant absorbed at time $t$ and at equilibrium, respectively. In addition, $D$ denotes mutual diffusion coefficient of the penetrant and $L$ is the half thickness of the polymer film. Crank ${ }^{9}$ has shown that at short times as $\mathrm{t} \rightarrow 0$, eq 2 can be simplified as follows:

$$
\frac{M_{t}-M_{\mathrm{o}}}{M_{\infty}-M_{\mathrm{o}}}=\frac{2}{\sqrt{\pi}}\left(\frac{D t}{L^{2}}\right)^{0.5}
$$

Because of its simplicity, in most of the gravimetric sorption studies, the diffusion coefficient is deduced from eq 3 by observing the initial slope of the $M_{t}-M_{\mathrm{o}} / M_{\infty}-M_{\mathrm{o}}$ versus $\sqrt{t}$ curve. This approach may give erroneous results if insufficient number of data points are collected at the beginning of the experiment. Based on this concern, we have determined the mutual diffusion coefficients through nonlinear least-squares analysis by minimizing the difference between the full analytical solution, that is eq 2 , and the experimental uptake curves.

\section{Correlation of Sorption Data}

The Flory-Huggins model is widely used to correlate sorption isotherms of polymer-solvent systems. According to this theory, the chemical potential difference between a solvent in a system, $\mu_{1}$, and in its pure state, $\mu_{10}$, or alternatively the activity of the solvent in vapor phase, $a_{1}$, is related to its volume fraction in the polymer, $\varphi_{1}$, by:

$$
\frac{\mu_{1}-\mu_{10}}{R T}=\ln a_{1}=\ln \varphi_{1}+\varphi_{2}+\chi \varphi_{2}^{2}
$$

Equation 4 is applicable to correlate isotherm data of polymer-solvent systems with simple thermodynamics described by a constant Flory-Huggins interaction parameter, $\chi$.

For cases where $\chi$ is a function of concentration, a modified form of eq 4 is needed. To derive a new chemical potential expression for a variable interaction parameter, one must consider the expression for the change in the Gibbs free energy, $\Delta G_{\text {mixing. }}{ }^{10}$

$\Delta G_{\text {mixing }}=N_{1} \ln \varphi_{1}+N_{1} \ln \varphi_{2}+\chi \varphi_{1} \varphi_{2}\left(N_{1}+r N_{2}\right)$

$$
\varphi_{1}=\frac{N_{1}}{N_{1}+r N_{2}} \quad \varphi_{2}=\frac{r N_{2}}{N_{1}+r N_{2}}
$$

In equations 5 and $6 N_{i}$ represents the number of molecules of $i, \varphi_{1}$ and $\varphi_{2}$ are the fractions of sites occupied by the solvent and polymer and $\mathrm{r}$ denotes segments in a polymer molecule. The activity of the solvent in vapor phase, $a_{1}$, is derived by differentiating the Gibbs free energy change with respect to the number of solvent molecules. For the

Journal of Polymer Science: Part B: Polymer Physics DOI 10.1002/polb 
case of constant $\chi$, one obtains eq 4 . If $\chi$ is concentration-dependent a modified version of the FloryHuggins equation is obtained, namely

$$
\begin{aligned}
\frac{\mu_{1}-\mu_{10}}{R T}=\ln a_{1}=\ln \varphi_{1}+\varphi_{2}+ & \chi \varphi_{2}^{2} \\
& +\varphi_{1} \varphi_{2}^{2} \frac{d \chi}{d \varphi_{1}}
\end{aligned}
$$

To use either eqs 4 or 7 , the solvent activities were calculated by assuming an ideal gas of pure solvent vapor and neglecting the vapor pressure of the polymer.

$$
a_{1}=\frac{P_{1}}{P_{1}^{\text {sat }}}
$$

where $P_{1}$ is the pressure of the solvent measured and $P_{1}^{\text {sat }}$ is the vapor pressure of the solvent at the column temperature which was taken from Daubert and Danner. ${ }^{11}$ The Flory-Huggins interaction parameter, either constant or concentration-dependent, was determined from nonlinear leastsquares analysis by comparing experimental data to the sorption models.

\section{Correlation of Diffusion Data}

Vrentas-Duda free volume theory provides a useful framework for both correlating and predicting diffusivities as a function of concentration and temperature. ${ }^{5,6}$ According to this theory, the self diffusion coefficient of the solvent, $D_{1}$, is expressed as follows:

$$
D_{1}=D_{\mathrm{o}} \exp \left(-\frac{E}{R T}\right) \times \exp \left(-\frac{\omega_{1} \hat{V}_{1}^{*}+\omega_{2} \hat{V}_{2}^{*} \xi}{\omega_{1} \frac{K_{11}}{\gamma}\left(K_{21}-T_{\mathrm{g} 1}+T\right)+\omega_{2} \frac{K_{12}}{\gamma}\left(K_{22}-T_{\mathrm{g} 2}+T\right)}\right)
$$

In eq $9, D_{\mathrm{o}}, E, \omega_{i}$ denote the preexponential constant, activation energy and weight fraction of component i (1: penetrant 2: polymer), respectively. The parameter groups $K_{11} / \gamma$ and $K_{21}-T_{\mathrm{g} 1}$ are free volume parameters of the penetrant while the groups $K_{12} / \gamma$ and $K_{22}-T_{\mathrm{g} 2}$ are free volume parameters of the polymer. In addition, $\hat{V}_{i}^{*}$ is the specific critical hole free volume of component $i$ and the parameter $\xi$ is defined as the ratio of the solvent to polymer jumping units involved in a diffusive step.

Incorporating the work of Bearman, ${ }^{12}$ Duda et al. ${ }^{13}$ proposed following relationship to couple the self diffusion coefficients to mutual diffusion coefficient, $D$.

$$
D=D_{1} Q
$$

Where thermodynamic factor $Q$ is defined as:

$$
\boldsymbol{Q}=\frac{\omega_{1} \omega_{2}}{R T}\left(\frac{\partial \mu_{1}}{\partial \omega_{1}}\right)_{\text {T.P }}
$$

By using the concentration-dependent $\chi$ form of the Flory-Huggins equation, that is eq 7 , the thermodynamic factor derived is:

$$
Q=\varphi_{2}^{2}\left[\left(1-2 \chi \varphi_{1}\right)+2 \varphi_{1}\left(\varphi_{2}-\varphi_{1}\right) \frac{d \chi}{d \varphi_{1}}\right]
$$

We note that for the case of a constant interaction parameter, eq 12 in conjunction with eq 10 leads to the most widely used form of the mutual diffusion coefficient, namely:

$$
D=D_{1} \varphi_{2}^{2}\left(1-2 \chi \varphi_{1}\right)
$$

\section{RESULTS AND DISCUSSION}

\section{Characterization of the Copolymer Film}

The glass transition temperature of the copolymer was determined as $40^{\circ} \mathrm{C}$ from DSC analysis shown in Figure 2. According to this figure, the copolymer is amorphous and starts to degrade around $327^{\circ} \mathrm{C}$. Figure 3 shows proton NMR spectrum of the copolymer. The rather complicated collection of NMR lines occurring between $0.5-2.5 \mathrm{ppm}$ are assigned to the alkyl methylene and methyl protons of the copolymer. The two isolated NMR lines occurring at 3.6 and $3.9 \mathrm{ppm}$ are assigned to the three protons of the -OCH3 methoxy substituent of MMA and the two alkoxy protons of the -OCH2 methylene group, respectively. Thus, by dividing the relative areas of these two NMR lines by 3 and 2 , respectively, as given in eq 14 , the composition of 
<smiles>CCC(C)(CC)C(=O)OC</smiles>

Methyl methacrylate

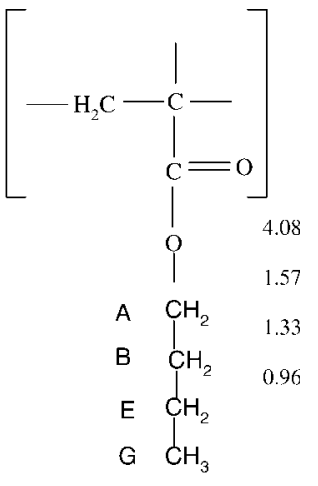

Butyl acrylate

the copolymer was calculated as $19.7 \%$ MMA and $80.3 \%$ BA by weight.

$$
\% M M A=\left(\frac{A_{3.6 \mathrm{ppm}} / 3}{A_{3.6 \mathrm{ppm}} / 3+A_{3.9} \mathrm{ppm} / 3}\right) \times 100
$$

For comparison, the composition of the copolymer was also calculated by applying the Flory-Fox equation ${ }^{14}$ :

$$
\frac{1}{T_{\mathrm{gc}}}=\frac{\omega_{\mathrm{MMA}}}{T_{\mathrm{g} . \mathrm{PMMA}}}+\frac{\omega_{\mathrm{BA}}}{T_{\mathrm{g} . \mathrm{PBA}}}
$$

where $T_{g c}$ is the glass transition temperature of the copolymer (measured as $313 \mathrm{~K}), T_{\mathrm{g}, \text { PMMA }}(381$ $\mathrm{K})$ and $T_{\mathrm{g}, \mathrm{PBA}}(300 \mathrm{~K})$ are the glass transition temperatures of the homopolymers polymethylmethacrylate (PMMA) and polybutylacrylate (PBA) and $\omega_{\mathrm{MMA}}$ and $\omega_{\mathrm{BA}}$ are the weight fractions of the MMA and BA units in the copolymer, respectively. The estimated weight percentages are 19.5 and $80.5 \%$, for MMA and BA, respectively. These values are close to those determined from NMR analysis,

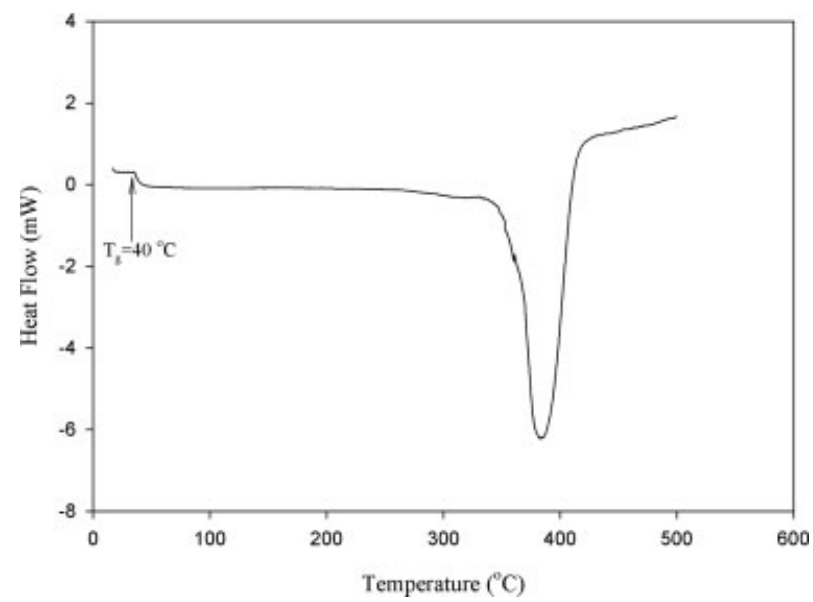

Figure 2. DSC analysis of the MMA-BA copolymer.

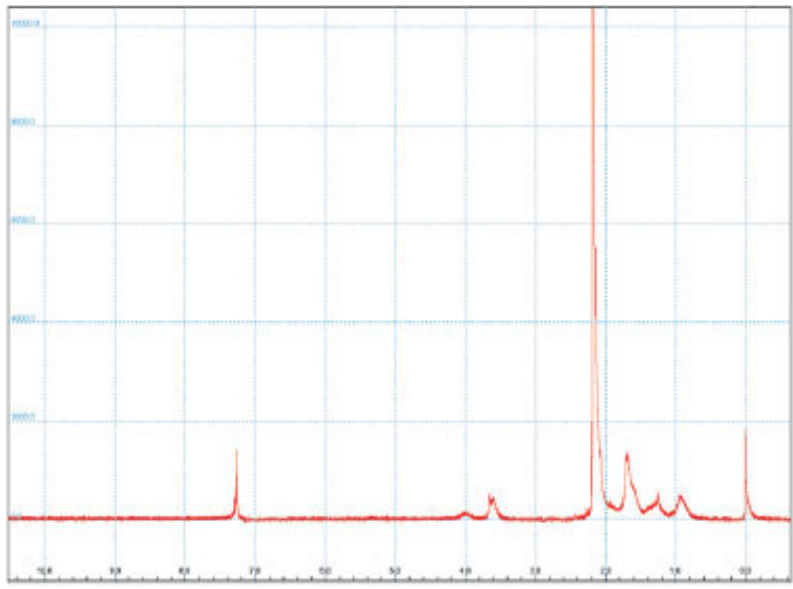

Figure 3. $1 \mathrm{H}$ NMR spectra of the MMA-BA copolymer. [Color figure can be viewed in the online issue, which is available at www.interscience.wiley.com.]

thus it appears that one can use eq 15 to estimate the composition of this copolymer system with reasonable accuracy if its glass transition temperature is measured.

\section{Vapor-Sorption Equilibria}

Equilibrium sorption isotherms of the binary systems MMA/MMA-BA and BA/MMA-BA copolymer were measured at 40,50 and $60{ }^{\circ} \mathrm{C}$. The density of the copolymer measured by gravimetric techniques is $1.07 \mathrm{~g} / \mathrm{cm}^{3}$ and the densities of solvents are 0.93 and $0.90 \mathrm{~g} / \mathrm{cm}^{3}$ for MMA and BA, respectively. These values were used to convert the weight fraction gravimetric sorption data to volume fractions, at all the temperatures considered, for analysis by the Flory-Huggins model. Experimental equilibrium solubilities of MMA in MMA-BA copolymer are illustrated in Figure 4. In the absence of concentration dependence, the thermodynamic interaction parameter, $\chi$, was determined as 0.55 . Except at high activities, Flory-Huggins theory with the constant interaction parameter provides a reasonably good fit for the equilibrium isotherms of the MMA/MMABA copolymer system. Sorption data for BA in the copolymer, however, are not correlated well with a constant interaction parameter. As a result, we have proposed the following expression to describe the concentration and temperature-dependence of the Flory-Huggins interaction parameter.

$$
\chi=a_{\mathrm{o}}+\frac{a_{1}}{T}+\left(a_{2}+\frac{a_{3}}{T}\right) \varphi_{1}
$$

where $a_{0}, a_{1}, a_{2}$, and $a_{3}$ are empirical constants. This relation is somewhat more general than other

Journal of Polymer Science: Part B: Polymer Physics DOI 10.1002/polb 


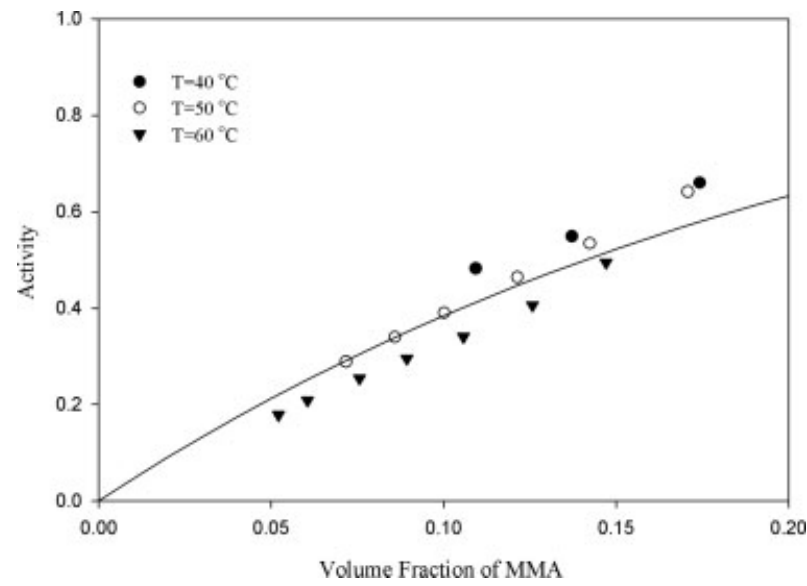

Figure 4. Equilibrium sorption data for the MMA/ MMA-BA copolymer system. The symbols and solid line represent experimental data and a correlation using the Flory-Huggins model with a constant $\chi$ parameter (eq 4), respectively.

expressions employed which ascribe either concentration or temperature dependence to the $\chi$ parameter. $^{15,16}$ Experimental equilibrium solubility correlations from eqs 7 and 16 are shown in Figure 5. The constants $a_{0}, a_{1}, a_{2}$, and $a_{3}$ in eq 16 were evaluated using the sorption data collected at 40,50 and $60{ }^{\circ} \mathrm{C}$ and were found to be $16.6,-5240,-26.3$, and 10,271 , respectively. The experimental data for this system reveal that BA interactions with the copolymer become less favorable as both temperature and concentration are increased. This result is also reflected in the values of the Flory-Huggins interaction parameter for BA/MMA-BA system given in eq 16. By using eqs 7 and 16, maximum solubilities of $\mathrm{BA}$ in the copolymer were predicted as $21.5,18$ and $14.4 \%$ by volume at 40,50 and $60{ }^{\circ} \mathrm{C}$, respectively. The sorption isotherms plotted in Figures 4 and 5 illustrate that maximum solubility of BA in the copolymer is smaller than that of the MMA. This may be attributable to the larger molecular size and branched structure of the BA monomer.

Aside from the difference in the temperature dependence of $\chi$, for these two systems, another interesting attribute of the sorption isotherms is the difference in their curvature. The MMA data are concave toward the volume fraction axis while the BA isotherms are concave toward the activity axis. Complex thermodynamic interactions are being clearly manifested. Although this type of behavior is interesting, it is not unique. ${ }^{17}$ We anticipate that our data will be particularly useful to both practitioners within the coatings industry and to thermodynamicists interested in testing fundamental models.

Journal of Polymer Science: Part B: Polymer Physics DOI 10.1002/polb

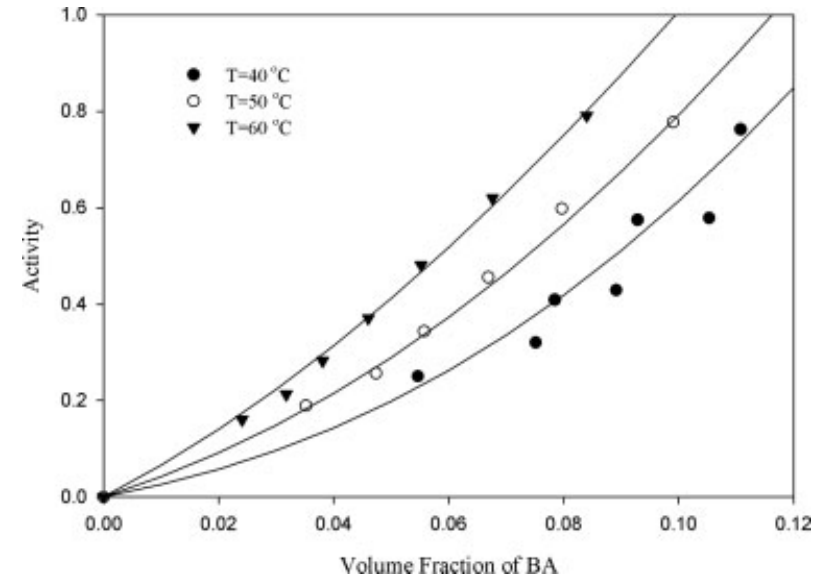

Figure 5. Equilibrium sorption data for the BA/MMABA copolymer system. The symbols represent experimental data and the lines are correlations using a modified form of the Flory-Huggins model, eqs 7 and 16, with a temperature and concentration-dependent $\chi$ parameter. The parameters for eq 16 which provide the best least-squares representation of the sorption data are $a_{\mathrm{o}}$ $=16.6, a_{1}=-5240, a_{2}=-26.3$ and $a_{3}=10,271$.

\section{Kinetic Studies}

Gravimetric sorption curves were collected at 40, 50 and $60{ }^{\circ} \mathrm{C}$ for MMA and BA monomers. The results are presented in terms of mass uptake $\left(M_{t}-\right.$ $M_{O}$ ) normalized with respect to the mass uptake level at long experimental times $\left(M_{\infty}-M_{O}\right)$ as a function of $\sqrt{t}$. Shown in Figures 6 and 7 are a series of sequential normalized uptake curves

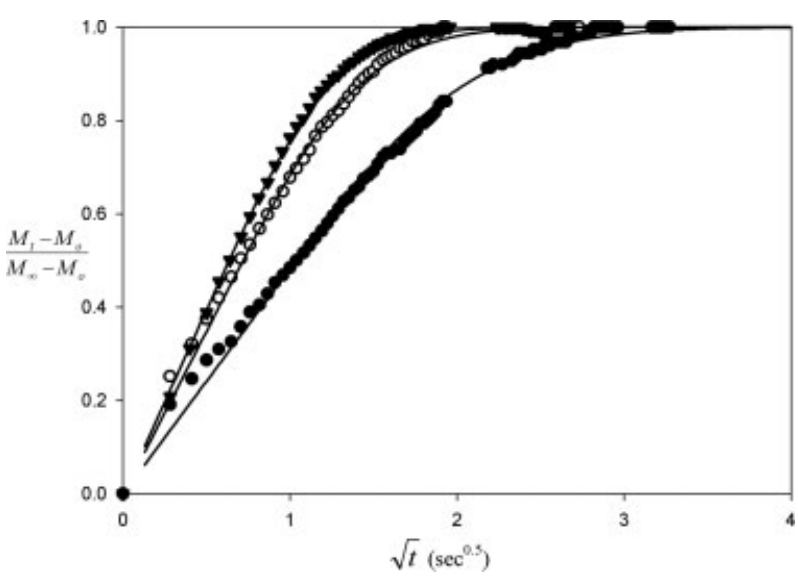

Figure 6. Fractional mass-uptake $\left(\frac{M_{t}-M_{o}}{M_{\infty}-M_{0}}\right)$ curves as a function of $\sqrt{t}$ for MMA sorption into MMABA copolymer at $T=50{ }^{\circ} \mathrm{C}$ at three different MMA vapor pressure intervals (in psia): $0.69-0.81$ [O] $0.93-1.10$ [○] and 1.27-1.52 [ $\mathbf{\nabla}$ ]. The symbols represent experimental data and the lines are correlations from eq 2. 


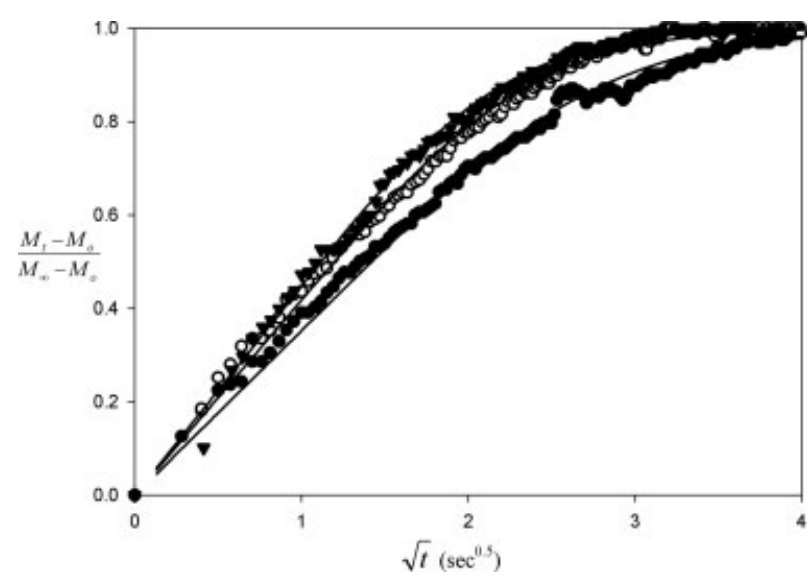

Figure 7. Fractional mass-uptake $\left(\frac{M_{t}-M_{o}}{M_{\infty}-M_{o}}\right)$ curves as a function of $\sqrt{t}$ for BA sorption into MMA-BA copolymer at $T=50{ }^{\circ} \mathrm{C}$ for three different BA pressure intervals (in psia): 0.11-0.14 [O] 0.14-0.19

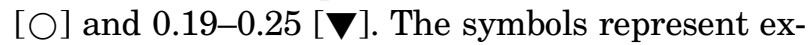
perimental data and the lines are correlations from eq 2.

obtained from the MMA and BA sorption into the copolymer at $50{ }^{\circ} \mathrm{C}$. The experimental conditions for the uptake experiments are listed in Tables 1 and 2. Experimental sorption steps were sufficiently small to enable the assumption that $D$ was constant during the course of a single experiment. This was verified by the good agreement observed between the transient sorption curves and the correlation provided by the Fickian analytical solution (eq 2). Consequently, the diffusion coefficients of MMA and BA into the copolymer could be evaluated from the full uptake curves.

Sample thickness change with increased solvent loading was estimated based on the assumption of isotropic swelling. Values of 2L, the total-thickness of the polymer system at the start of the sorption step, are provided in Tables 1 and 2 . It is important to account for this thickness change during the evaluation of diffusion coefficients since $\mathrm{D}$ is related to the square of the sample thickness (eqs 2 and 3). In addition, the value of $\mathrm{D}$ measured from a step-change experiment was associated with a weighted concentration average within that interval. Vrentas and Duda ${ }^{18}$ revealed that minimal error was introduced if the average concentration was associated with $70 \%$ of the sorption interval if $\mathrm{D}$ was found to be increasing with the addition of solvent or at $56 \%$ of the sorption interval if $\mathrm{D}$ was found to decreasing with increasing concentration.

The results listed in Tables 1 and 2 indicate that: a) the diffusion rates of the MMA and BA monomers have similar temperature dependencies, however, the concentration dependence of MMA monomer diffusion coefficient is stronger than that of the BA monomer. b) The diffusion coefficient of BA monomer is smaller than that of

Table 1. Diffusivity Data for MMA/MMA-BA Copolymer at 40, 50, and $60^{\circ} \mathrm{C}$

\begin{tabular}{|c|c|c|c|c|c|c|c|}
\hline \multirow{2}{*}{$\begin{array}{c}\text { Temperature } \\
\left({ }^{\circ} \mathbf{C}\right)\end{array}$} & \multicolumn{2}{|c|}{ Pressure (psi) } & \multicolumn{3}{|c|}{$\omega_{\mathrm{MMA}}$} & \multirow{2}{*}{$\begin{array}{c}\text { Total } \\
\text { Thickness } \\
(2 \mathrm{~L})(\mu \mathrm{m})\end{array}$} & \multirow{2}{*}{$\begin{array}{l}D \times 10^{8} \\
\left(\mathrm{~cm}^{2} / \mathrm{s}\right)\end{array}$} \\
\hline & Initial & Final & Initial & Equilibrium & Average $^{a}$ & & \\
\hline \multirow[t]{5}{*}{40} & 0.000 & 0.72 & 0.00 & 0.10 & 0.07 & 64.3 & 3.37 \\
\hline & 0.72 & 0.82 & 0.10 & 0.12 & 0.11 & 71.2 & 7.00 \\
\hline & 0.82 & 0.99 & 0.12 & 0.16 & 0.15 & 73.3 & 8.40 \\
\hline & 0.99 & 1.13 & 0.16 & 0.18 & 0.17 & 76.2 & 9.67 \\
\hline & 1.13 & 1.29 & 0.18 & 0.21 & 0.20 & 78.7 & 12.00 \\
\hline \multirow[t]{7}{*}{50} & 0.000 & 0.69 & 0.00 & 0.06 & 0.04 & 63.3 & 1.44 \\
\hline & 0.69 & 0.81 & 0.06 & 0.08 & 0.07 & 68.2 & 3.54 \\
\hline & 0.81 & 0.93 & 0.07 & 0.09 & 0.08 & 69.3 & 5.34 \\
\hline & 0.93 & 1.10 & 0.09 & 0.11 & 0.10 & 70.4 & 7.85 \\
\hline & 1.10 & 1.27 & 0.11 & 0.13 & 0.12 & 72.1 & 10.08 \\
\hline & 1.27 & 1.52 & 0.13 & 0.15 & 0.14 & 73.8 & 11.08 \\
\hline & 1.52 & 1.89 & 0.15 & 0.19 & 0.18 & 76.4 & 14.60 \\
\hline \multirow[t]{6}{*}{60} & 0.000 & 0.65 & 0.00 & 0.05 & 0.03 & 65.0 & 1.90 \\
\hline & 0.65 & 0.76 & 0.05 & 0.06 & 0.05 & 68.6 & 3.86 \\
\hline & 0.76 & 0.93 & 0.06 & 0.07 & 0.06 & 69.2 & 4.56 \\
\hline & 0.93 & 1.08 & 0.07 & 0.08 & 0.07 & 70.3 & 5.71 \\
\hline & 1.08 & 1.24 & 0.08 & 0.09 & 0.09 & 71.4 & 6.85 \\
\hline & 1.24 & 1.48 & 0.09 & 0.11 & 0.11 & 72.7 & 7.85 \\
\hline
\end{tabular}

${ }^{\text {a }}$ Evaluated at $\omega_{\mathrm{MMA}}$ given by $\omega_{\mathrm{MMA}}($ initial $)+0.7\left[\omega_{\mathrm{MMA}}(\right.$ equilibrium $)-\omega_{\mathrm{MMA}}($ initial $\left.)\right]$. 
Table 2. Diffusivity Data for BA/MMA-BA Copolymer at 40,50 , and $60{ }^{\circ} \mathrm{C}$

\begin{tabular}{|c|c|c|c|c|c|c|c|}
\hline \multirow{2}{*}{$\begin{array}{l}\text { Temperature } \\
\left({ }^{\circ} \mathrm{C}\right)\end{array}$} & \multicolumn{2}{|c|}{ Pressure (psi) } & \multicolumn{3}{|c|}{$\omega_{\mathrm{BA}}$} & \multirow{2}{*}{$\begin{array}{c}\text { Total } \\
\text { Thickness } \\
(2 \mathrm{~L})(\mu \mathrm{m})\end{array}$} & \multirow{2}{*}{$\begin{array}{l}D \times 10^{8} \\
\left(\mathrm{~cm}^{2} / \mathrm{s}\right)\end{array}$} \\
\hline & Initial & Final & Initial & Equilibrium & Average $^{a}$ & & \\
\hline \multirow[t]{3}{*}{40} & 0.00 & 0.06 & 0.00 & 0.02 & 0.01 & 30.0 & 0.16 \\
\hline & 0.10 & 0.14 & 0.07 & 0.08 & 0.08 & 32.6 & 2.20 \\
\hline & 0.14 & 0.19 & 0.08 & 0.10 & 0.09 & 33.1 & 3.20 \\
\hline \multirow[t]{4}{*}{50} & 0.11 & 0.14 & 0.04 & 0.05 & 0.04 & 31.4 & 1.60 \\
\hline & 0.14 & 0.19 & 0.05 & 0.06 & 0.05 & 31.7 & 2.30 \\
\hline & 0.19 & 0.25 & 0.06 & 0.07 & 0.06 & 32.1 & 2.70 \\
\hline & 0.25 & 0.32 & 0.07 & 0.08 & 0.07 & 32.5 & 2.90 \\
\hline \multirow[t]{7}{*}{60} & 0.00 & 0.11 & 0.00 & 0.02 & 0.01 & 30.0 & 0.90 \\
\hline & 0.11 & 0.14 & 0.02 & 0.03 & 0.02 & 30.7 & 1.80 \\
\hline & 0.14 & 0.19 & 0.03 & 0.04 & 0.03 & 30.9 & 1.90 \\
\hline & 0.19 & 0.25 & 0.04 & 0.038 & 0.036 & 31.1 & 2.00 \\
\hline & 0.25 & 0.32 & 0.038 & 0.046 & 0.043 & 31.4 & 2.30 \\
\hline & 0.32 & 0.41 & 0.046 & 0.058 & 0.054 & 31.7 & 3.10 \\
\hline & 0.41 & 0.53 & 0.058 & 0.076 & 0.071 & 32.2 & 3.80 \\
\hline
\end{tabular}

${ }^{\text {a }}$ Evaluated at $\omega_{\mathrm{BA}}$ given by $\omega_{\mathrm{BA}}($ initial $)+0.7\left[\omega_{\mathrm{BA}}(\right.$ equilibrium $)-\omega_{\mathrm{BA}}($ initial $\left.)\right]$.

MMA monomer because of its larger and more branched molecular structure.

To determine the nature of the diffusion, the sorption experiments at the same step sizes were performed with different sample thicknesses. In Figures 8 and 9, normalized mass uptake curves are plotted against $\frac{\sqrt{t}}{L}$ using data measured on samples with two different thicknesses. As shown in Figure 9, in the case of BA sorption two new samples were examined whose total thicknesses were 58 and $70 \mu \mathrm{m}$, compared to our original sample of

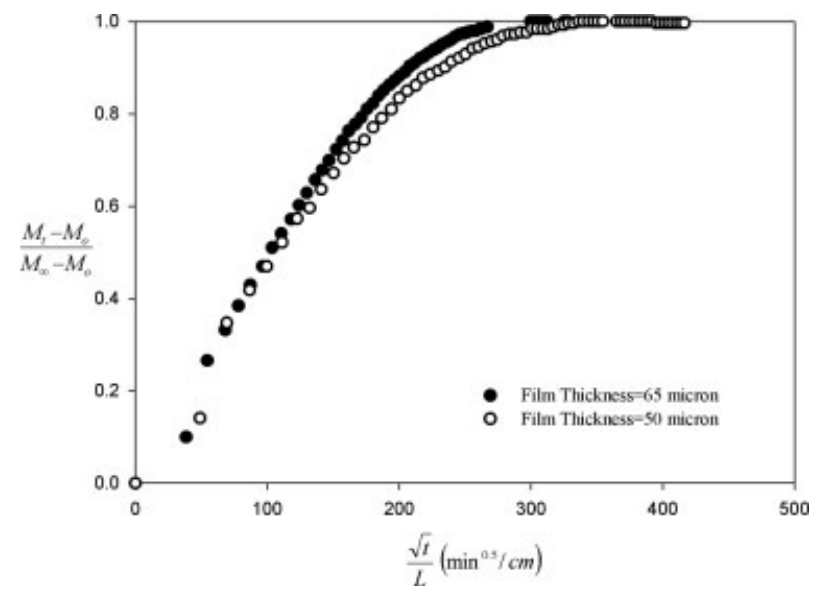

Figure 8. Mass-uptake $\left(\frac{M_{t}-M_{o}}{M_{\infty}-M_{o}}\right)$ curves collected from the samples with two different thicknesses as a function of $\frac{\sqrt{t}}{L}$ for MMA sorption into MMA-BA copolymer at $T=40{ }^{\circ} \mathrm{C}$ for the MMA pressure interval 0.81-0.98 psia.
$30 \mu \mathrm{m}$. The results shown in Figures 6 through 9 indicate that MMA and BA diffusivity in the MMA-BA copolymer can be categorized as Fickian since (a) the initial trend in the normalized uptake data is linear with respect to $\sqrt{t}$ while the latter (higher $t$ ) part of the curves are concave with respect to the $\sqrt{t}$ axis (b) the curves monotonically increase to a plateau (c) the curves do not exhibit an inflection point and (d) the curves collected from the samples with different thicknesses coincide with each other.

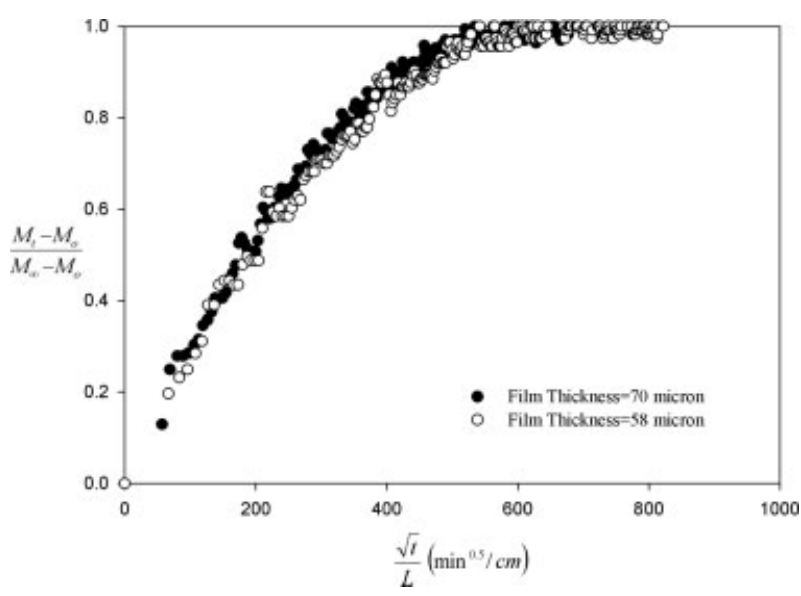

Figure 9. Mass-uptake $\left(\frac{M_{t}-M_{o}}{M_{\infty}-M_{o}}\right)$ curves collected from the samples with two different thicknesses as a function of $\frac{\sqrt{t}}{L}$ for BA sorption into MMA-BA copolymer $T=60{ }^{\circ} \mathrm{C}$ for the BA pressure interval $0.19-0.26$ psia. 


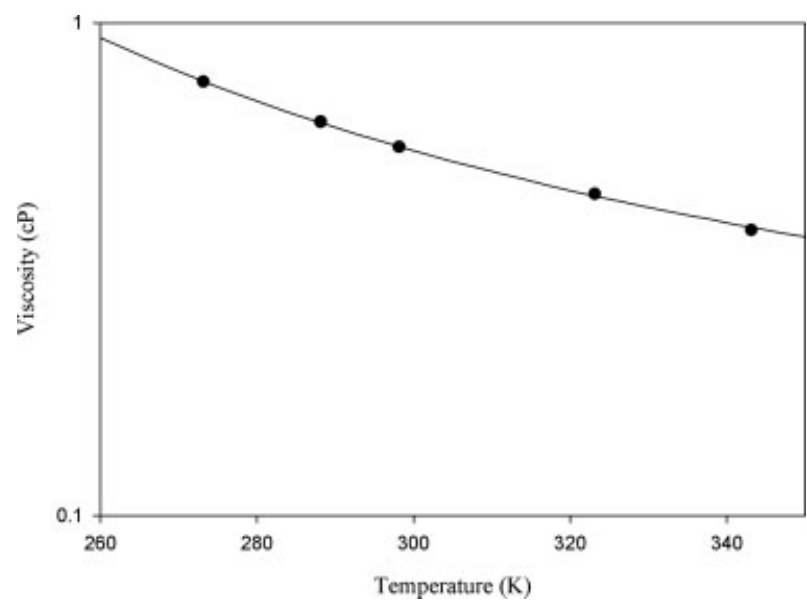

Figure 10. Viscosity data for MMA as a function of temperature (From Riddle, Monomeric Acrylic Esters, Reinhold, New York, 1954). Solid line represents a data correlation using the Vogel-Fulcher-Tammann equation (eq 17).

\section{Correlation of Diffusivity Data}

To correlate the diffusivity data using VrentasDuda free volume theory, we first determined the free volume parameters for the monomers and the copolymer. Using the viscosity data given in Figures 10 and 11, the MMA and BA free volume parameters $\left(K_{11} / \gamma, K_{21}-T_{\mathrm{g}} 1\right)$ were calculated from the Vogel-Fulcher-Tammann viscosity model. ${ }^{19-21}$

$$
\ln \eta_{1}=\ln A_{1}+\left(\frac{\frac{\gamma \hat{V}_{1}^{*}}{K_{11}}}{K_{21}-T_{\mathrm{g} 1}+T}\right)
$$

The values estimated from nonlinear least-squares analyses are given in Table 3 . The copolymer free volume parameters $\left(K_{12} / \gamma, K_{22}-T_{\mathrm{g} 2}\right)$ were determined independently from rheological measurements and are also provided in Table 3 .

The specific critical hole free volume of the monomers, $\hat{V}_{i}^{*}$, were estimated as the specific volume of an equilibrium liquid at $0 \mathrm{~K}$. The group contribution method developed by Sugden ${ }^{26}$ and Biltz $^{27}$ yields values of 0.871 and $0.905 \mathrm{~cm}^{3} / \mathrm{g}$ for MMA and BA monomers, respectively. By using the composition of the copolymer and $\hat{V}_{2}^{*}$ values of the homopolymers, PMMA $\left(0.789 \mathrm{~cm}^{3} / \mathrm{g}\right)$ and PBA $\left(0.843 \mathrm{~cm}^{3} / \mathrm{g}\right)$, the specific critical hole free volume of the copolymer was calculated as follows:

$$
\hat{V}_{2}^{*}=x_{\mathrm{MMA}} \hat{V}_{2, \mathrm{PMMA}}^{*}+x_{\mathrm{BA}} \hat{V}_{2, \mathrm{PBA}}^{*}
$$

where $x_{\mathrm{MMA}}$ and $x_{\mathrm{BA}}$ are the mole fractions of the MMA and BA units in the copolymer. The other pa-

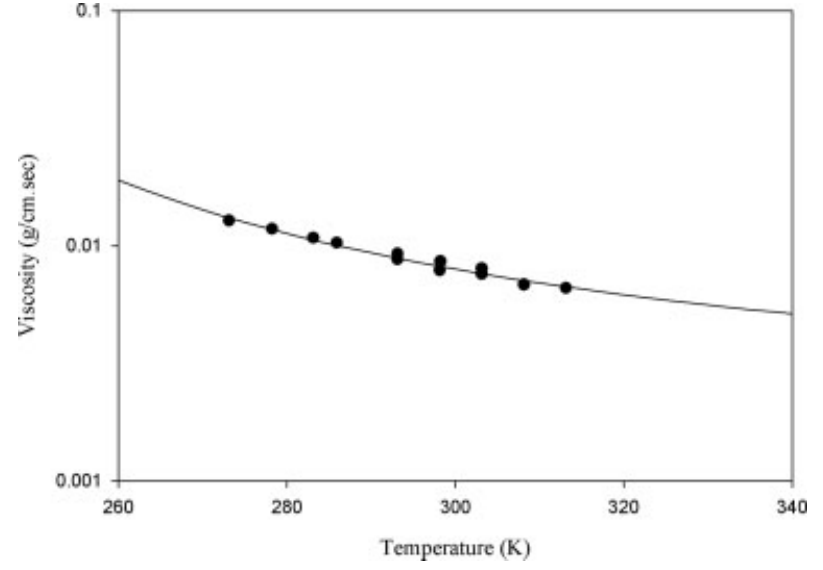

Figure 11. Viscosity data for BA as a function of temperature (From AIChE DIPPR Project 801, 1998, AIChE; Sastry et al., Int J Thermophys 1997, 18, 1387; Liau et al., J Chem Eng Data 1998, 43, 826.) Solid line represents a data correlation using the Vogel-FulcherTammann equation (eq 17).

rameters which appear in Vrentas-Duda free volume theory, $D_{0}, E$, and $\xi$, are correlative parameters. These parameters were evaluated comparing eqs 9,10 , and 12 to the diffusion data collected at $40{ }^{\circ} \mathrm{C}$ and at 40,50 and $60^{\circ} \mathrm{C}$ in the cases of MMA and $\mathrm{BA}$ diffusion into the copolymer, respectively, and performing a least squares analysis to minimize the sum of the squares of the residuals. The parameters are listed in Table 3.

Table 3. Free-Volume Parameters Used to Correlate the Data in Figures 12 and 13

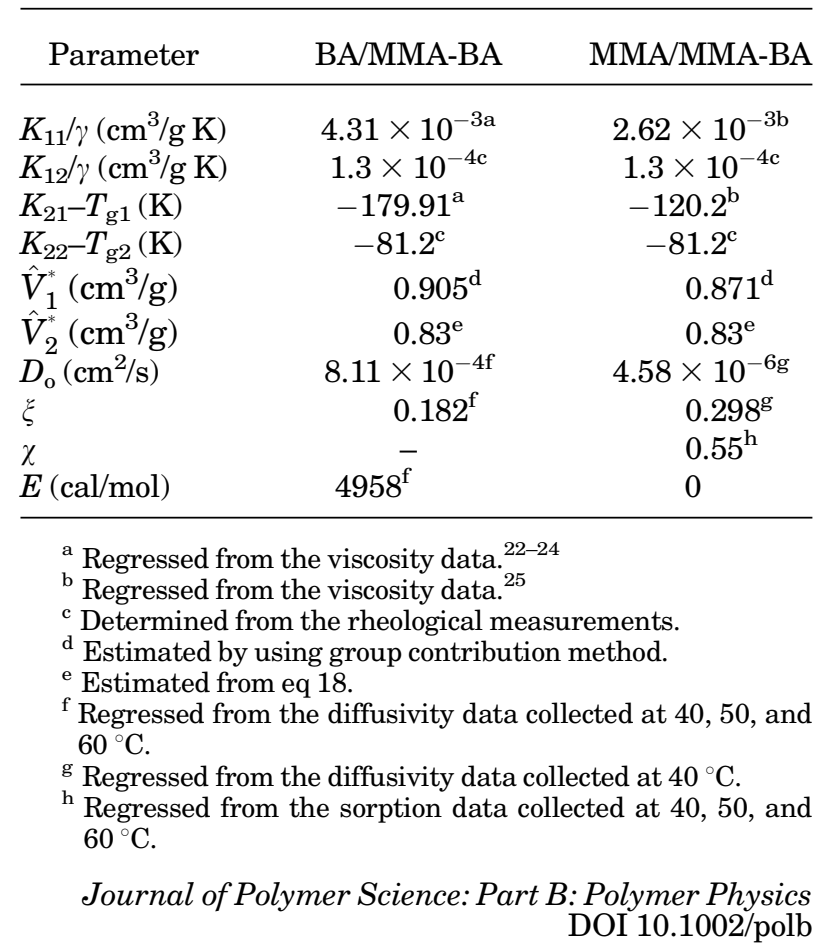


If data are measured over a relatively small temperature range, the activation energy for a molecule to break free from nearest neighbors, $E$, can often be set equal to 0 and the temperature dependence for diffusion can still be adequately captured by the dependence of free volume on temperature using an effective pre-exponential Do value which appropriately scales the diffusion coefficient values. This has been done in Figure 12 which shows a 2-parameter free volume correlation of the $40{ }^{\circ} \mathrm{C}$ data (using eqs 9 and 13) and subsequent predictions of the MMA diffusion data at 50 and $60{ }^{\circ} \mathrm{C}$. Within the certainty of the experimental data, the deviation between the free volume curves and the data is insignificant. In summary, by performing a free volume correlation of diffusion data at one temperature $\left(40{ }^{\circ} \mathrm{C}\right)$ one can accurately predict diffusion behavior at other temperatures (50 and $60^{\circ} \mathrm{C}$ ), not too significantly removed from the correlated data set, by assuming $E$ equals 0 .

If a traditional 3-parameter FV analysis is performed, the resulting values for $D_{\mathrm{o}}, E$, and $\xi$, are $2.39 \times 10^{-5} \mathrm{~cm}^{2} / \mathrm{s}, 900 \mathrm{cal} / \mathrm{mol}$, and 0.325 , respectively, and the FV curves represent the diffusion data somewhat better at the three temperatures examined. More importantly, however, these parameters enable diffusion predictions to be made over a broader temperature range with more confidence. Since the BA copolymer system exhibited a temperature and concentration-dependent $\chi$ parameter, eqs 9,12 , and 16 were used to correlate the diffusion data. These parameters are provided in Table 3. Despite the variable polymer-solvent

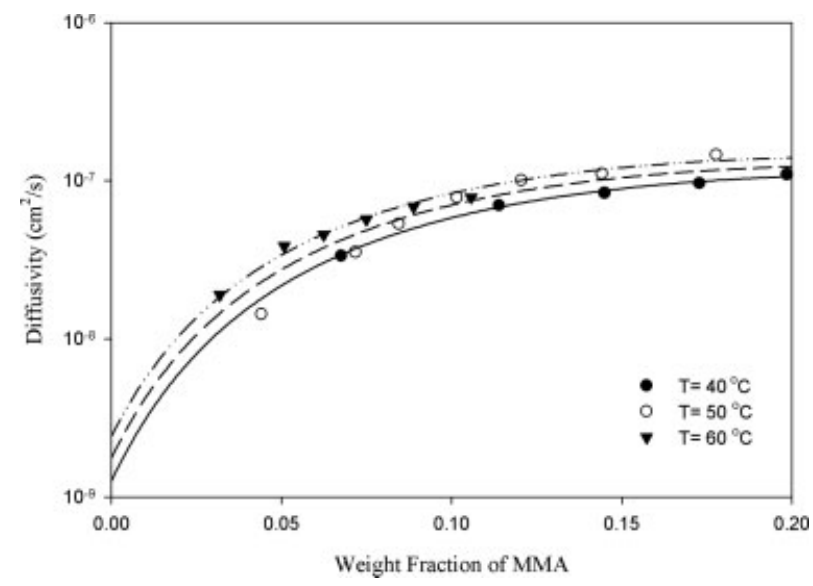

Figure 12. Experimental data and free-volume theory representation (full lines) for MMA/MMA-BA copolymer system. The $40{ }^{\circ} \mathrm{C}$ data were correlated by performing a least-squares analysis for $D_{\mathrm{o}}$ and $\xi$, with the assumption that $\mathrm{E}$ equals zero. Thus, the $40{ }^{\circ} \mathrm{C}$ line is a free-volume correlation while the 50 and $60{ }^{\circ} \mathrm{C}$ lines are predictions.

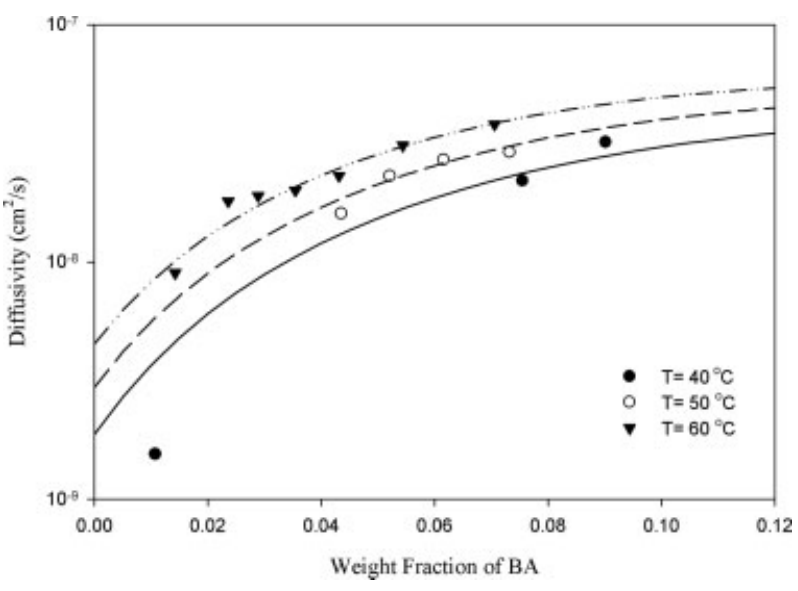

Figure 13. Experimental data and free-volume theory correlations (full lines) for the BA/MMA-BA copolymer system.

thermodynamic interactions exhibited by this system, the free-volume diffusion model provides a good correlation of the experimental data as shown in Figure 13. Some deviation is apparent between the model and the datum at the lowest temperature and concentration examined. This may be due to errors in the concentration-dependence of the thermodynamic term in eq 10 or in uncertainties in the viscosity data used in the evaluation of BA free volume parameters.

Although BA is larger in size than MMA, the jump size unit for BA diffusion within the copolymer is found to be smaller than for MMA from the relative values of $\xi$. This finding suggests that BA undergoes segmental diffusion and is consistent with the observation that the concentration dependence of the MMA monomer diffusion coefficient is stronger than that of the BA monomer in this copolymer. More diffusion data for other solvents are required before one can comment on whether MMA diffuses segmentally or as a whole molecule.

Lastly, in the 3 parameter FV correlations of the BA and MMA data, resulting values of the activation energy to break free from nearest neighbors, $\mathrm{E}$, were found to be $4958 \mathrm{cal} / \mathrm{mol}$ for BA and 900 for MMA. These values are significantly lower than the diffusion activation energy associated with the free-volume temperature dependence ${ }^{28}$ as is expected for a polymer/penetrant system near its glass transition temperature.

\section{CONCLUSIONS}

In this study, solubility and mutual diffusion data for both MMA and BA monomers in a MMA-BA 
copolymer have been measured by a gravimetric sorption technique. Sorption results reveal that $\mathrm{BA}$ is less soluble in the copolymer than MMA because of its larger and more branched structure. MMA sorption can be correlated with a constant Flory Huggins interaction parameter. In the case of BA sorption, the data are best correlated with a temperature and concentration-dependent interaction parameter. Sorption studies indicate that both MMA and BA diffusion into the MMA-BA copolymer exhibit Fickian-type transport. MMA diffusivity is found to be faster and shows a stronger concentration dependence than BA diffusivity. The diffusivity data for MMA was correlated and predicted well with Vrentas-Duda free volume theory. Despite the variable polymer-solvent thermodynamic interactions exhibited by the BA copolymer system, the free-volume diffusion model provides a good correlation of the experimental data, although some deviation is apparent between the model and the data at the lowest temperature and concentration examined.

The data reported here are of interest especially for the paint industry. They can be applied not only in the design of devolatilization units required to produce environmentally friendly paints but also in predicting the emission characteristics of the monomers from the paint when applied on indoor and outdoor surfaces.

The authors like to thanks TÜBİTAK (National Science Foundation of TURKEY) and Izmir Institute of Technology for the financial support through Grants MISAG 144 and 1999MÜH 04/2001MÜH 16. We also gratefully acknowledge Organik Kimya A.S. for providing the chemicals, Surya Mallapragada for NMR analysis and David Venerus and Ritesh Nair for rheological measurements.

\section{REFERENCES AND NOTES}

1. Faldi, A.; Tirrell M.; Lodge, T.; von Meerwall, E. Macromolecules 1994, 27, 4184.

2. Griffiths, M. C.; Strauch, J.; Monteiro, M. J.; Gilbert, R. G. Macromolecules 1998, 31, 7835.

3. Tonge, M. P.; Stubbs, J. M.; Sundberg, D. C.; Gilbert, R. G. Macromolecules 2000, 41, 3659.
4. Gilbert, R. G. Emulsion Polymerization: A Mechanistic Approach; Academic Press: London, 1995.

5. Vrentas, J. S.; Duda, J. L. J Polym Sci Part B: Polym Phys 1977, 15, 403.

6. Vrentas, J. S.; Duda, J. L. J Polym Sci Part B: Polym Phys 1977, 15, 417.

7. Kleinrahm, R.; Wagner, W. J. J Chem Thermodyn 1986, 18, 739 .

8. Sato, Y.; Takikawa, T.; Takishima, S.; Masuoka, H. J Supercrit Fluids 2001, 19, 187.

9. Crank, J. The Mathematics of Diffusion, 2nd ed.; Oxford University Press: Oxford, 1975.

10. Prausnitz, J.; Lichtenthaler, R. N.; de Azevedo, E. G. Molecular Thermodynamics of Fluid Phase Equilibria, 2nd ed.; Prentice Hall: New Jersey, 1986.

11. Daubert, T. E.; Danner, R. P. Physical and Thermodynamic Properties of Pure Chemicals: Data Compilation; Hemisphere Publishing: New York, 1989.

12. Bearman, R. J. J Phys Chem 1961, 65, 1961.

13. Duda, J. L.; Vrentas, J. S.; Ju, S. T.; Liu, H. T. AIChE J 1982, 28, 297.

14. Fox, T. G. Bull Am Phys Soc 1956, 1, 123.

15. Schuld, N.; Wolf, B. A. J Polym Sci Part B: Polym Phys 2001, 39, 651.

16. Schuld, N.; Wolf, B. A. In Polymer Handbook; Brandrup, J.; Immergut, E. H.; Grulke, E. A., Eds.; Wiley: New York, 1999; Chapter VII, 247-264.

17. Palamara, J. E.; Mulcahy, K. A.; Jones, A. T.; Danner, R. P.; Duda, J. L. Ind Eng Chem Res 2005, 44, 9943.

18. Vrentas, J. S.; Duda, J. L.; Ni, Y. C. J Polym Sci Polym Phys Ed 1977, 15, 2039.

19. Vogel, H. Z Phys 1921, 22, 645.

20. Fulcher, G. S. J Am Ceram Soc 1925, 8, 339.

21. Tammann, G.; Hesse, W. Z. Z Anorg Allg Chem 1926, 156, 245.

22. American Institute of Chem Engineers (AIChE). Design Institute for Physical Properties (DIPPR) Project 801, Evaluated Process Design Data; AIChE: New York, 1998.

23. Sastry, N. V.; Valand, M. K. Int J Thermophys 1997, $18,1387$.

24. Liau, W.-R.; Tang, M.; Chen, Y.-P. J Chem Eng Data 1998, 43, 826.

25. Riddle, E. H. Monomeric Acrylic Esters; Reinhold: New York, 1954.

26. Sugden, S. J Chem Soc 1927, 1786.

27. Biltz, W. Rauchemie der Festen Stoffe; Voss: Leipzig, 1934.

28. Vrentas, J. S.; Duda, J. L. J Polym Sci Polym Phys Ed 1979, 17, 1085. 